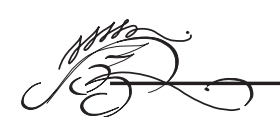

\title{
Methods for overcoming communication difficulties
}

\author{
Tatiana Laguta, \\ Candidate of Philology, Associate Professor, \\ Olga Verzhanskaya, \\ Candidate of Philosophy, Associate Professor, \\ Kharkiv National University by V. N. Karazin
}

T1 he development of inter-ethnic and intercultural relations and global processes of globalization have necessitated foreign language skills at the professional level professionals in different fields. In order to be successful and competitive, today is not enough to know your business, you need to constantly improve, to take into account the experience, including international. In this connection, an increasing need for a new level of training of future specialists in the field of foreign languages. Its absence in the future may lead to a systematic communication failure, ie failure speaking communicative intentions.

The work is dedicated to the study of the phenomenon of "communicative failure."Despite some theoretical achievements of scientists (B. Gorodetsky, I. Kobozeva, I. Saburov, A. Ermakov, Dmitry Gudkov, N. Formanovskaya et al.) this question is not enough studied. The presence of identical concepts, complexity and diversity of this phenomenon, the variability of its causes, cause at the same time the interest of scientists and division of views on this phenomenon. The relevance of the study is to explore the means to optimize communication in a cross-cultural interaction.

Failures communicative nature happen for a variety of reasons, ranging from the wrong interpretation of gestures, ending the lack of awareness in the field of professional terminology. To future specialists did not have problems, foreign language teachers should think about performing a variety of tasks. The teacher must not only provide the basis, but also to teach students to independently use a foreign language to solve various problems and continue to improve in the possession of language.

The first problem causes the necessity of forming a high level of cross-cultural competence memories and the spectrum of background knowledge. Lack of understanding of the pattern of other people of the world can affect the perception of damage and successful communication. In the communication process may adversely affect misperception speech situation, lack of experience of the conversations with other cultures, incorrect estimates of verbal behavior, the concept of interaction rules, general lack of knowledge about the world.

It is necessary to emphasize the importance of the three components that can change the course of conversation: the need for specific knowledge about the ways of cooperation in various speech situations and about the factors that determine, understanding communicative intentions of the partner and the associated expectations of certain actions. These

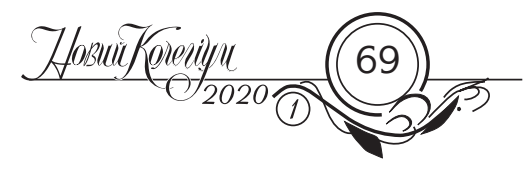


components suggest the presence of the four levels of perceptions: philosophical, cultural, communication and language. If at least in one direction, there are gaps, communication can not reach its goal. To avoid this, you need to instruct students from every aspect.

It is also important psychological effect, since the presence of certain ideas can not guarantee the possibility of using existing knowledge in practice.

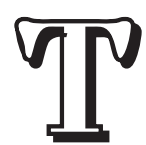

he sources of communication failure may be different parts of

the communicative text: word, saying a speech product, a set of speech products. A big role in the occurrence of communication failures can play differences in the byorganization of language thesaurus communicants. Communication failure may occur at different levels of understanding of the process, from the morphological and syntactic analysis to the understanding and practical interlocutor communication purposes. Numerous communication failures associated with different stages of verbalization, first of all, to the stage of the plan, if it does not meet the situational context. Psihosotsiolingvistichni especially the communicants can also cause communication failure.

The researchers also point out the role of situational, social and cultural context. [4] Situational context is considered as a set of components of the communicative situation: the time and place, the degree of formality / informality, members and the like. Sociocultural context provides a set of norms and rules of conduct specific to a particular situation, and based on the values of the culture that is the background to communicate communicants.

A more efficient way to prepare the future expert Intercultural duration is the formation of certain acts of communication. One business practices are role-playing and simulation games, during which students can take the place of one of the interlocutors and play the whole communication process from start to finish. However, for qualitative performance of the role of the student must be familiar with the worldview, cultural and social realities.

Cultural knowledge includes an idea of the specifics of the customs, traditions and way of life, depending on which communication takes on a peculiar character. Manners, the assumption that the speech partner's intentions and expectations of certain actions on his part caused by, first of all, existing stereotypes, that is, images and characteristics that we endow representatives of other nations. According to the degree of stability of patterns can be divided into the superficial and deep [3, c. 96]. The first is with the passage of time will depend on the political, economic and cultural policies of the countries quite ambiguous. Second, on the contrary, it is characterized by a certain constancy and stability.

On the communicative level, cause of failure in communication may be inaccurate, reticence in expressing thoughts or misunderstanding of speech intention, that is, to carry out the intentions of the speaker addressed a speech act of practical or mental nature [6, c. 107]. Incompleteness may be associated with the use of indirect forms of representation intentions. The reasons for such hidden meanings is often polite and mitigate categorical as communication objectives expressed openly, could debase the addressee, contrary to the rules of etiquette, or be unpleasant for the interlocutor. Thus it is necessary to distinguish between the actual information and communication. First constructed in order to transfer an unknown information, the second - to maintain relationships. For the second type of indirect communication characteristic expression speech problems, which causes misunderstanding [2, c. 18-20].

In order to optimize the voice action often resort to installations on cooperative communication, which is based on compliance with the ethical standards of language [5, c. 27]. However, apart from the wording of inaccuracies and misunderstandings speech intention, cause

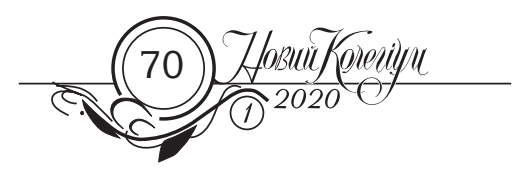


great difficulties gaps in language training. The greatest difficulties arise from the experts with specialized terminology, as well as in cases of interference of the native language. However, not enough to know the individual elements of the system of language, the main thing - to be able to use the personal armory for the implementation of communication tasks on a professional level, requires a full commitment to practical implementation.

The most professional way to learn a foreign language communication is the exchange of knowledge in action, one form of which - educational business game. The advantage of the business game is the ability of the interconnected training of all kinds of speech activity. In addition, it contains a search of meaningful professional and cultural information, the formulation of the basic ideas in mind and completed the preparation of presentations, role playing, suggests the involvement of all the information processing channels.

Live chat allows you to overcome the psychological barrier and to prepare students for the future implementation of professional communication that helps reduce the risk of occurrence of communication failures. Regular carrying out this kind of business games contributes to the development of communication skills in a foreign language, and allows graduates to higher education in the future to achieve the implementation of their intentions in the negotiations in a foreign language.

Features dialogical communication as speech forms do not allow at the time of communication completely avoid communication failures, however, a correct understanding of communication failures as a phenomenon, knowledge of the factors that determine the appearance of failures in communication, and the ability to adequately select the adjustment mechanism, depending on the causes of communication failures contribute to overcoming failures in communication and increase the efficiency of voice interactions.
Among successful communication conditions investigators [4] are the following: 1. Communicative interest. 2. Adjusting to the light source, the proximity of attitude of the speaker and the hearer (including verbal forms of properly adjusting the light listener author calls intonation, tone of voice, rate of speech, repetition, special means of expression of the speaker's attitude to the subject of speech (adjectives, adverbs evaluation, opening words and offers), pauses, silence). 3. Uminnya listeners understand the communicative intent of the speaker. 4 . The ability to vary the way to the speaker's linguistic representation of one or another real event. Talking builds his message with a focus on the world of knowledge recipient, adapting the presentation of information to the possibilities of its interpretation.

Favorable external circumstances, such as a channel of communication, mood, emotional, physiological state, is also very important. The conversation consists of replicas, pauses, tempo, gestures, facial expressions, views key; conversation evolves over time, and each subsequent replica superimposed on everything said above, interact with it, so the result of this interaction can be unpredictable.

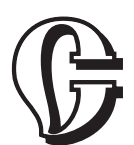
ompliance with these conditions of compliance and well known principles -. Relevance principle D. Sperber and D. Wilson, G. Grice cooperation principle characterizing the operating procedure for sharing information in the structure and principle of communicative act courtesy J. Leach, R. Lakoff, the observance of which creates a positive medium interaction, provides favorable conditions for the implementation of communication strategies by means such as stroke, approval, agreement, sympathy, respect the boundaries of the private sphere of the interlocutor positively st in the evaluation of the other, the search for years, goodwill, and minimizes communication failures, conflict communicative situation.

We believe that teachers should pay extra attention to the specifics of the national

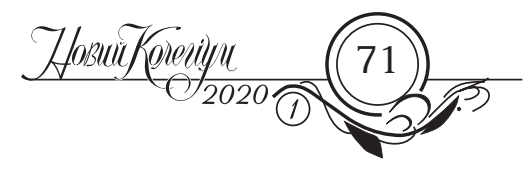


style of communication within the courses of sociolinguistics, lingvostranovedeniya. Should be used to this end, watching videos, reading fiction, attract resources of the Internet. Dramatizing the situation, from books dialogues, films and books in which clearly visible differences in communicative behavior and speech patterns, students not only acquire knowledge, but also to acquire the application of new skills of speech samples. The challenge to stage a dialogue on the Ukrainian (Russian) language on behalf of people of different ages and social status, and allows you to better understand the features of the Ukrainian (Russian) communicative culture, form a tolerant attitude to the verbal behavior of other cultures.

Promising is the study of the phenomenon of communication failures and their solutions on the linguistic material of various ethnic groups.

\section{Literature}

1. Vereshchagin E. M. Language and culture / E.M. Vereshchagin, V.G. Kostomarov. Moscow : Indrikis, 2005. $1038 \mathrm{p}$.

2. Maksimov VI Russian language and culture of speech : Textbook. Moscow : Gardariki, 2001. 413 p.

3. Pavlovskaya A.V. Ethnic stereotypes in the light of intercultural communication. Moscow : Moscow State University, 1998. $278 \mathrm{p}$.

4. Pushina N.I. Communicative Failures in Intercultural Communication: causes, types, strategies to minimize / N.I. Pushina, N.. Mahankova, E.A. Wide // Bulletin of Udmurt University. "History and Philology" series. 2015. №6. URL: https://cyberleninka.ru/ article/n/kommunikativnye-neudachi-vmezhkulturnoy-kommunikatsii-prichinytipologiya-strategii-minimizatsii.

5. Sedov K. F. Anthology speech genres. Moscow, 2007. 320 p.

6. Formanovskaya N.I. Culture of communication and speech etiquette. Moscow : ICAR, 2005. 250 p.

20.07.2019 